Bull. Mater. Sci., Vol. 35, No. 4, August 2012, pp. 645-649. (C) Indian Academy of Sciences.

\title{
Effect of substrate type, dopant and thermal treatment on physicochemical properties of $\mathrm{TiO}_{2}-\mathrm{SnO}_{2}$ sol-gel films
}

\author{
I STAMBOLOVA*，V BLASKOV，S VASSILEV ${ }^{\dagger}$, M SHIPOCHKA and A LOUKANOV \\ Institute of General and Inorganic Chemistry, ${ }^{\dagger}$ Institute of Electrochemistry and Energy Systems, BAS, \\ Acad. G. Bonchev Str., bl.11, 1113 Sofia, Bulgaria \\ †Department of Engineering Geoecology, University of Mining and Geology, Stoyan Edrev Str., 1700 Sofia, Bulgaria
}

MS received 11 April 2011; revised 18 May 2011

\begin{abstract}
Thin nanocrystalline $\mathrm{TiO}_{2}-\mathrm{SnO}_{2}$ films (0-50 mol\% $\left.\mathrm{SnO}_{2}\right)$ were prepared on quartz and stainless steel substrates by sol-gel coating method. The obtained films were investigated by XRD, Raman spectroscopy and XPS. The size of the nanocrystallites was determined by XRD-LB measurements. We ascertained that the increase of treatment temperature and concentration of $\mathrm{SnO}_{2}$ in the films favour the crystallization of rutile phase. The substrate type influences more substantially the phase composition of the $\mathrm{TiO}_{2}-\mathrm{SnO}_{2}$ films. It was established that a penetration of elements took place from the substrate into the films. $\mathrm{TiO}_{2}$ films deposited on quartz substrate include a Si which stabilizes anatase phase up to $600^{\circ} \mathrm{C}$. The films which are deposited on stainless steel substrate and treated at $700^{\circ} \mathrm{C}$ show the presence of significant quantity of rutile phase. This phenomenon could be explained by the combined effect of $\mathrm{Sn}$ dopant as well as $\mathrm{Fe}$ and $\mathrm{Cr}$, which also are penetrated in the films from the steel substrate. The titania films doped up to $10 \mathrm{~mol} \% \mathrm{SnO}_{2}$ on stainless steel possess only 12-17 $\mathrm{nm}$ anatase crystallites, whereas the $\mathrm{TiO}_{2}-(10-50 \mathrm{~mol} \%) \mathrm{SnO}_{2}$ films contain very fine grain rutile phase $(4 \mathrm{~nm})$.
\end{abstract}

Keywords. $\quad \mathrm{TiO}_{2}-\mathrm{SnO}_{2}$ films; sol-gel; anatase; rutile; quartz substrate; stainless steel substrate.

\section{Introduction}

Titania $\left(\mathrm{TiO}_{2}\right)$ has recently attracted much attention because of its large surface area and pores, which are of great importance in self-cleaning glasses, gas sensors, optical thin-layer instruments, antireflection coatings for photovoltaic cells, photo chromic devices (Hoffman et al 1995; Traversa et al 1996; Garzella et al 2000; Miyauchi et al 2002; Habibi et al 2007; Shen et al 2009) etc. The choice of the dopant in titania may play a crucial role in the crystalline structure and phase transformation temperature of $\mathrm{TiO}_{2}$ thin films. The $\mathrm{TiO}_{2}-\mathrm{SnO}_{2}$ system is attractive due to the close ionic radii, equivalency, thermal stability and advantages for environmental improvements. A coupled $\mathrm{TiO}_{2}-\mathrm{SnO}_{2}$ photocatalyst has been reported to work efficiently for degradation of various organic pollutants under UV-VIS irradiation (Kanai et al 2004; Maeda and Hirota 2006; Zhou et al 2008; Tu et al 2009; El-Maghraby 2010). It is known that the $\mathrm{SnO}_{2}$ influences some physicochemical properties of $\mathrm{TiO}_{2}$, especially when the addition of $\mathrm{SnO}_{2}$ to titania films reduces the size of the crystallites and inhibits their growth (Lin et al 1999; Zakrzewska 2001; Liu et al 2002). The literature review about crystalline stability of $\mathrm{TiO}_{2}-\mathrm{SnO}_{2}$ system is still confused. It was indicated that tin oxide in $\mathrm{TiO}_{2}-\mathrm{SnO}_{2}$ binary oxides stabilizes the anatase phase up to $700{ }^{\circ} \mathrm{C}$ (Liu et al 2002; Yang et al 2002), however, other reports revealed that

\footnotetext{
*Author for correspondence (stambolova@yahoo.com)
}

the addition of $\mathrm{SnO}_{2}$ serves as a nuclei for the phase transformation and reduce the anatase-rutile transition temperature (Tai and Oh 2002; Mahanty et al 2004; Kumar et al 2007). There is a lack of systematic studies concerning the effect of the type of used substrate on the phase composition and crystallite size of $\mathrm{TiO}_{2}$ and $\mathrm{TiO}_{2}-\mathrm{SnO}_{2}$ films, especially in the cases when the films are deposited on steel substrates. This investigation is of great importance concerning the possible applications of them as photocatalytic electrodes (Kaya et al 2005) and anticorrosion coatings (Fallet et al 2001). Fernandez et al (1995) have proved migration of some cations from the support to the $\mathrm{TiO}_{2}$ layers: $\mathrm{Na}^{+}$and $\mathrm{Si}^{4+}$ from glass and $\mathrm{Fe}^{3+}$ and $\mathrm{Cr}^{3+}$ from stainless steel, which has detrimental effect on the photocatalytic activity of the films. In our previous report about $\mathrm{TiO}_{2}-\mathrm{SnO}_{2}$ sprayed films on quartz and stainless steel, we have found that the type of substrate and $\mathrm{SnO}_{2}$ content in the films has a significant effect on the phase composition and anatase phase stability (Stambolova et al 2010).

The aim of this paper is to investigate the influence of thermal treatment temperature, type of the substrate and concentration of tin dioxide in $\mathrm{TiO}_{2}$ films on anatase-phase stability and size of the crystallites of titania sol-gel films.

\section{Experimental}

Titanium precursor solution was prepared by mixing $0.35 \mathrm{M}$ $\mathrm{Ti}(i \text {-OPr })_{4}$ with acetylacetone and dissolving in isopropanolwater mixture. The resultant solution had molar ratio 
between $\mathrm{Ti}(i-\mathrm{OPr})_{4}: A c A c: \mathrm{H}_{2} \mathrm{O}: i s o \mathrm{PrOH}=1: 1: 1: 30$. Then the titania sol was mixed with $0.2 \mathrm{M} \mathrm{SnCl}_{4}$ in ethanolic solution in order to obtain final sols with $0-50 \mathrm{~mol} \%$ tin dioxide. To prevent the hydrolysis of $\mathrm{SnCl}_{4}$ solution, a few drops of $\mathrm{HNO}_{3}$ were added to the reaction mixture. Finally $10 \mathrm{wt} \%$ polyethyleneglycol (PEG) with a molecular weight of 400 was added to the mixture of $\mathrm{Ti}(\mathrm{OPr})_{4}$ and $\mathrm{SnCl}_{4}$ under vigorous stirring and the final polymeric solution was continuously stirred for $1 \mathrm{~h}$. Quartz and stainless steel were used in order to investigate the effect of substrate type. The quartz substrates were cleaned successively with dichromate mixture, mixture of hydrochloric acid and nitric acid (3:1), ethanol and acetone. The stainless steel plates were cleaned successively in hot ethanol and acetone. The substrate were coated with sol solution by spin-on technique, and then dried after every deposition at 60,100 and $300^{\circ} \mathrm{C}$ for $10 \mathrm{~min}$. The drying procedure was repeated four times. The final thermal treatment (after froth drying) was carried out in air at 500$800^{\circ} \mathrm{C}$ for $60 \mathrm{~min}$ and thick films $(\sim 150 \mathrm{~nm})$ were obtained. The crystalline phase composition of the samples was studied by X-ray diffraction (XRD) using X-ray diffractometer (Philips PW 1050) with $\mathrm{CuK}_{\alpha}$ radiation. XRD-LB measurements were carried out in order to estimate the crystallite size. Raman spectra were recorded using a SPEX 1403 double spectrometer, equipped with a photomultiplier, working in photon counting mode. The $488 \mathrm{~nm}$ line of an $\mathrm{Ar}^{+}$ion laser was used for excitation. The chemical composition and electronic properties of the titania layers were investigated by X-ray photoelectron spectroscopy (XPS). The measurements were performed in a VG ESCALAB II electron spectrometer using $\mathrm{AlK}_{\alpha}$ radiation with an energy of $1486 \cdot 6 . \mathrm{eV}$.

\section{Results and discussion}

\subsection{Films deposited on quartz substrate}

Figure 1 presents the Raman spectra of the sol-gel $\mathrm{TiO}_{2}$ doped with 1-15 mol\% $\mathrm{SnO}_{2}$ films on quartz substrates and annealed at $500^{\circ} \mathrm{C}$. Raman peaks at $144,197,396,516$ and $638 \mathrm{~cm}^{-1}$ are assigned to the anatase phase (Buska et al 1994). The Raman spectra for the $\mathrm{TiO}_{2}$ films doped with 20 and $50 \mathrm{~mol} \% \mathrm{SnO}_{2}$ have only peaks assigned to the substrate used. XRD profiles of these films indicate the presence of anatase phase. The anatase crystallites remain after annealing at $600^{\circ} \mathrm{C}$. Rutile becomes the main crystalline phase for all films investigated after heat treatment at $700{ }^{\circ} \mathrm{C}$. XPS analysis revealed that the films include silicon content and is in the range $2.5-3.5$ at $\%$. This might be explained by interaction of quartz substrate with films. We have observed similar process for sprayed $\mathrm{ZrO}_{2}$ films, which are deposited on quartz substrate (Peshev et al 2003). The possible mechanism used in the interaction is not yet clear. Probably $\mathrm{SiO}_{2}$ inclusion in sol-gel films might stabilize the anatase phase. This hypothesis is in accordance with the results obtained by Yoshinaka et al (1997), where it is proved that the addition of $5 \mathrm{~mol} \%$ $\mathrm{SiO}_{2}$ to $\mathrm{TiO}_{2}$ has some retarding effect on the anatase to

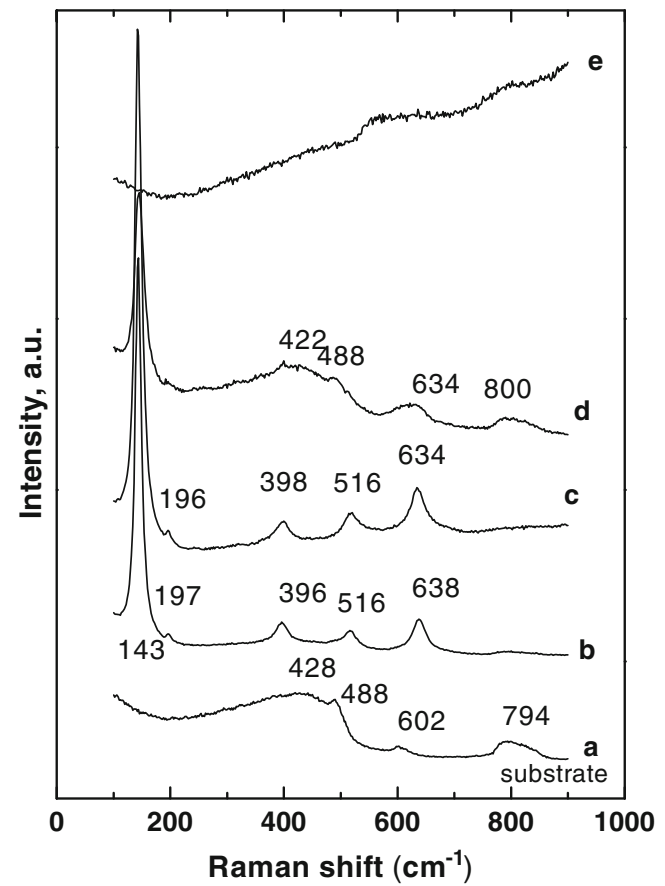

Figure 1. Raman spectra of sol-gel $\mathrm{TiO}_{2}$ films doped with different $\mathrm{SnO}_{2}$ contents, annealed at $500^{\circ} \mathrm{C}$ on quartz substrates: (a) substrate, (b) $1 \mathrm{~mol} \%$, (c) $5 \mathrm{~mol} \%$, (d) $10 \mathrm{~mol} \%$ and (e) $50 \mathrm{~mol} \%$.

rutile transformation. In conformation, Nikolic et al (2005) have found that the transformation rate of $\mathrm{TiO}_{2}$ sol-gel films is lower on quartz and single crystal quartz than on alumina substrate.

\subsection{Films deposited on stainless steel substrate}

XRD profiles of pure titania films and films doped with 3 and $5 \mathrm{~mol} \% \mathrm{SnO}_{2}$ (treated at $500{ }^{\circ} \mathrm{C}$ ) indicate that only the peaks are assigned to anatase crystallites (figures $2 \mathrm{a}-$ c). Rutile peaks are observed for the sample doped with $10 \mathrm{~mol}_{\mathrm{S} \mathrm{SnO}_{2}}$ (figure 2d). With the increase of tin dioxide content in the films, peaks assigned to anatase fade out and the rutile peaks appear. Undoped titania films annealed at $700^{\circ} \mathrm{C}$ show mainly anatase phase with traces of rutile, (figure 3). All sol-gel films doped with $\mathrm{SnO}_{2}(10-50 \mathrm{~mol} \%)$ and treated at $600-700^{\circ} \mathrm{C}$ contain mainly rutile phase. The cassiterite phase has not been registered by XRD analysis probably due to the fact that $\mathrm{SnO}_{2}$ peak overlaps with the strongest rutile one or it is in the amorphous state. Figure 4 shows X-ray diffractogram of $\mathrm{TiO}_{2}$ doped with $10 \mathrm{~mol} \% \mathrm{SnO}_{2}$ after treatment at $700^{\circ} \mathrm{C}$. It is known that the rutile phase is the most stable when the grain size is $>35 \mathrm{~nm}$ (Zhang and Banfield 2000). In the $\mathrm{TiO}_{2}-\mathrm{SnO}_{2}$ films deposited on steel substrates, a lower anatase-rutile transformation is observed despite smaller crystallites of size less than $35 \mathrm{~nm}$. Subsequently, the introduction of $\mathrm{SnO}_{2}$ to our titania films probably has more pronounced effect on the transformation to rutile than size of the crystallites. The possible explanation is that 
the cassiterite has a rutile structure and thus promotes phase transition (Ding et al 1994; Mahanty et al 2004).

The chemical composition of sol-gel $\mathrm{TiO}_{2}-\mathrm{SnO}_{2}(0-50$ mol\%) films was investigated by XPS. XPS analysis indicated some interaction between stainless steel substrate and

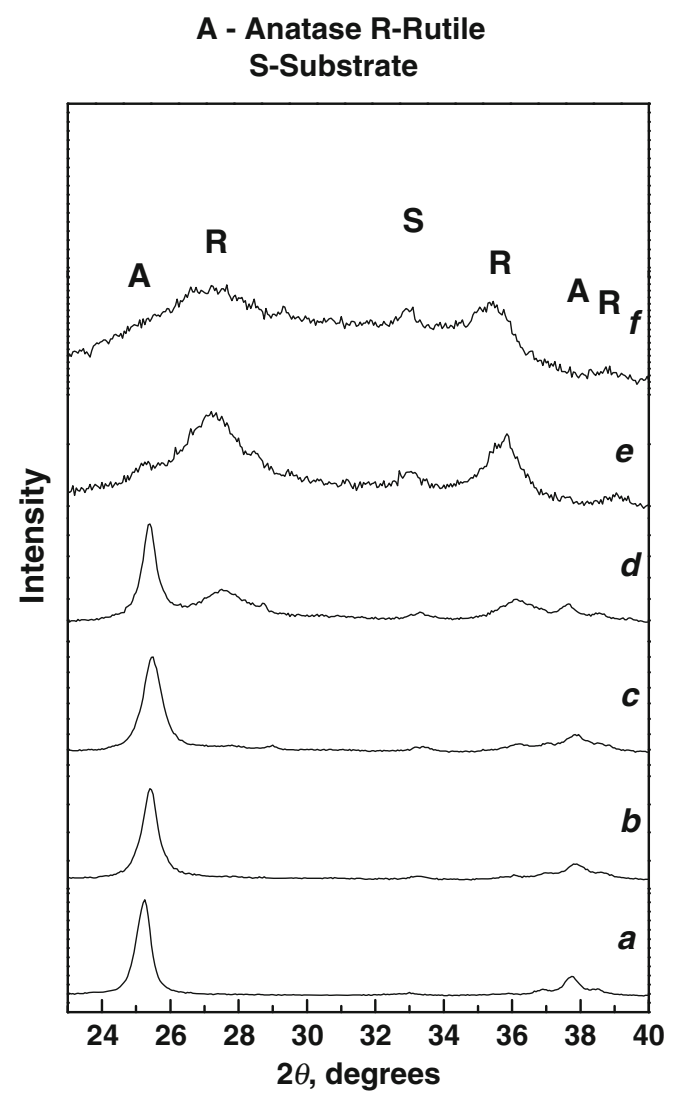

Figure 2. XRD spectra of sol-gel $\mathrm{TiO}_{2}$ films doped with different $\mathrm{SnO}_{2}$ contents, annealed at $500{ }^{\circ} \mathrm{C}$ on stainless steel: (a) $0 \mathrm{~mol} \%$, (b) $3 \mathrm{~mol} \%$, (c) $5 \mathrm{~mol} \%$, (d) $10 \mathrm{~mol} \%$, (e) $20 \mathrm{~mol} \%$ and (f) $50 \mathrm{~mol} \%$.

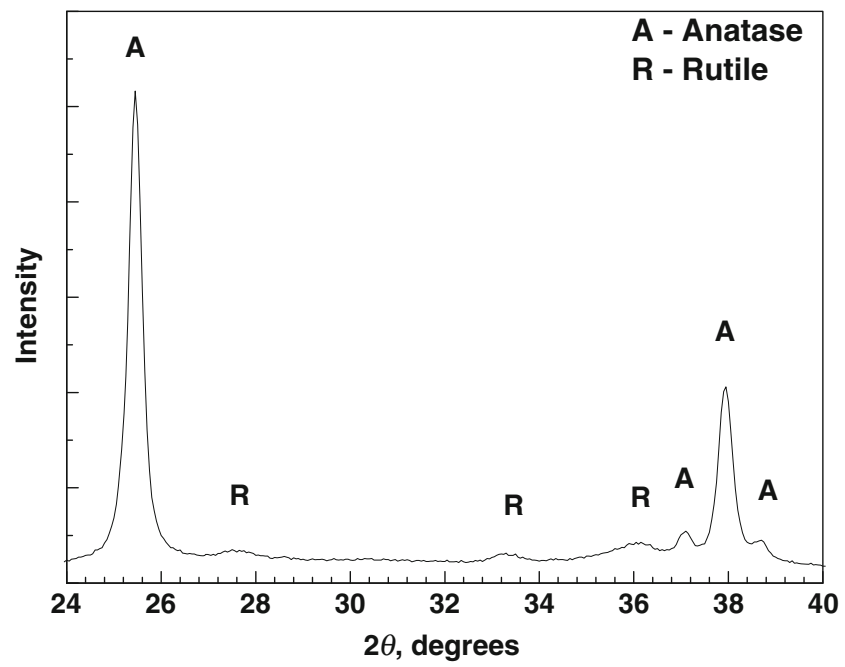

Figure 3. XRD spectra of sol-gel $\mathrm{TiO}_{2}$ films, annealed at $700{ }^{\circ} \mathrm{C}$ on stainless steel. films likely in the case of films deposited on quartz substrate. It was established that 4 at $\%$ iron from stainless steel substrate penetrates into the films and the concentration is not changed with treatment at temperatures up to $700^{\circ} \mathrm{C}$. Gennari and Pasquevich (1998) revealed that the dopant $\mathrm{Fe}_{2} \mathrm{O}_{3}$ decreases the phase transition temperature of $\mathrm{TiO}_{2}$ powdery samples. The strong promoting effect of iron addition to titania on the anatase-rutile transition has been established also by other workers (MacKenzie 1975; Zhang and Reller 2002).

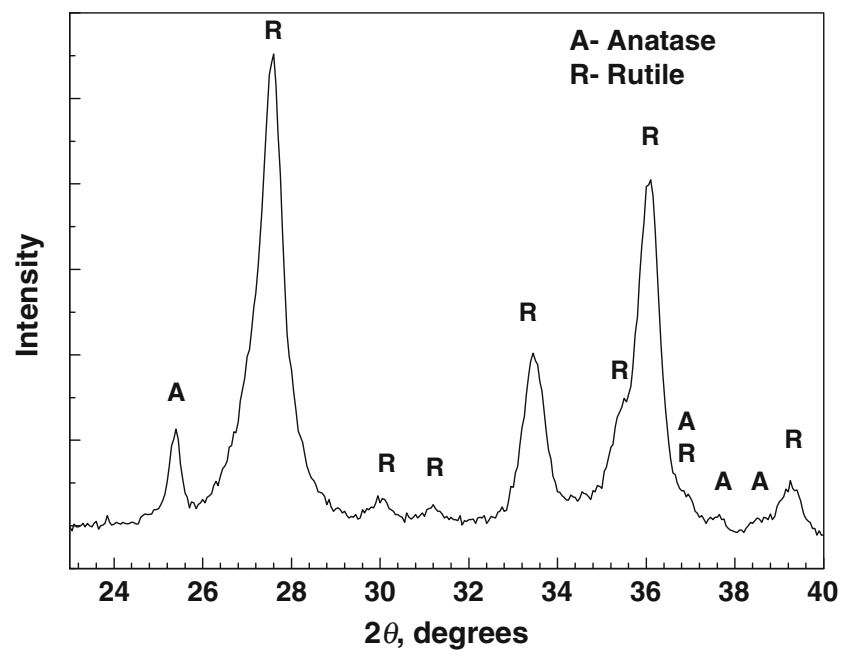

Figure 4. XRD spectra of sol-gel $\mathrm{TiO}_{2}$ films doped with $10 \mathrm{~mol} \% \mathrm{SnO}_{2}$, annealed at $700{ }^{\circ} \mathrm{C}$ on stainless steel.

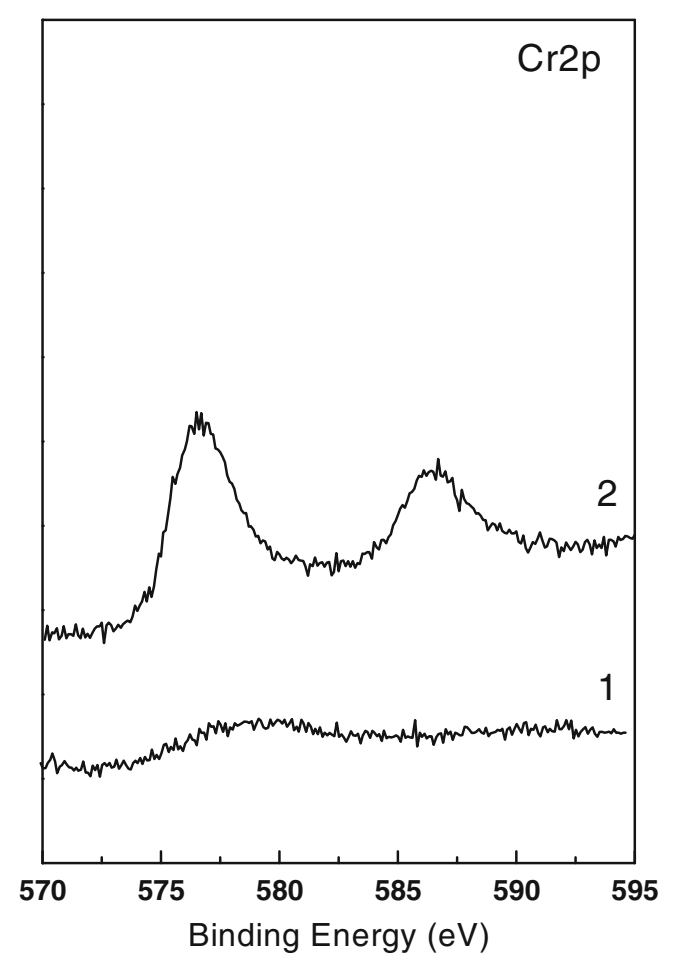

Figure 5. XPS spectra of $\mathrm{Cr} 2 p$ of $\mathrm{TiO}_{2}$ sol-gel films on stainless steel: (1) $\mathrm{TiO}_{2}$ treated at $500{ }^{\circ} \mathrm{C}$ and (2) $\mathrm{TiO}_{2}-10 \mathrm{~mol} \% \mathrm{SnO}_{2}$, treated at $700{ }^{\circ} \mathrm{C}$. 


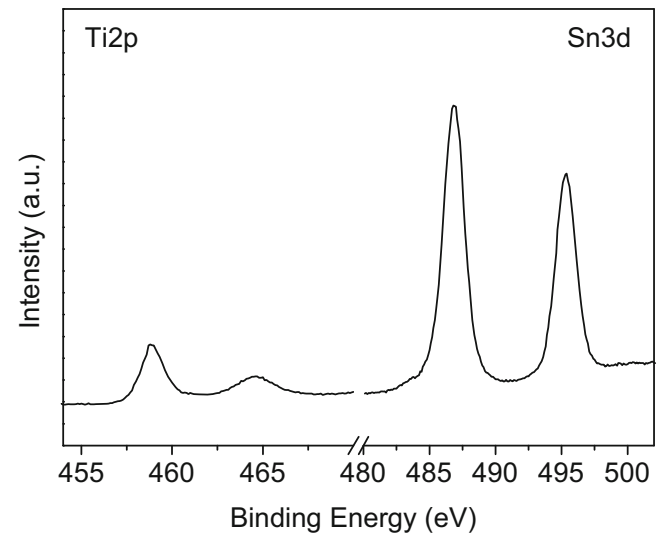

Figure 6. XPS spectra of $\mathrm{Ti} 2 p$ and $\mathrm{Sn} 3 d$ of $\mathrm{TiO}_{2}-20 \mathrm{~mol} \% \mathrm{SnO}_{2}$ sol-gel films on stainless steel treated at $500^{\circ} \mathrm{C}$.

Table 1. Size of anatase crystallites in $\mathrm{TiO}_{2}-\mathrm{SnO}_{2}$ sol-gel films after thermal treatment at $500^{\circ} \mathrm{C}$.

\begin{tabular}{lcc}
\hline $\begin{array}{l}\text { Sample } \\
\left(\mathrm{mol}_{\mathrm{SnO}}\right)\end{array}$ & $\begin{array}{c}\text { Crystalline size } \\
\text { for films deposited } \\
\text { on quartz } \\
\text { substrate }(\mathrm{nm})\end{array}$ & $\begin{array}{c}\text { Crystalline size } \\
\text { for films deposited } \\
\text { on stainless } \\
\text { steel substrate }(\mathrm{nm})\end{array}$ \\
\hline 0 & 16 & 16 \\
1 & 16 & 15 \\
3 & 15 & 15 \\
5 & 14 & $12 \cdot 5$ \\
10 & 14 & 17 \\
20 & 14 & - \\
50 & $14 \cdot 5$ & (4 for rutile phase) \\
& & - \\
& & (5 for rutile phase)
\end{tabular}

It was established that chromium penetrates from the steel substrate into the films treated at $500^{\circ} \mathrm{C}$. The X-ray photoelectron spectrum of the $\mathrm{Cr} 2 p$ region for titania films, treated at 500 and $700{ }^{\circ} \mathrm{C}$ is shown in figure 5 . The concentration of $\mathrm{Cr}$ in the films was about 2 at $\%$ at $500^{\circ} \mathrm{C}$. The thermal treatment at $700^{\circ} \mathrm{C}$ caused more pronounced diffusion of chromium ion from the steel substrate and its concentration in the films increases up to 6.7 at $\%$. The addition of $1 \mathrm{~mol} \%$ $\mathrm{Cr}$ into titania powder leads to $9 \%$ rutile phase according to the investigation of MacKenzie (1975). A partial rutilization of $\mathrm{TiO}_{2}$ supported catalyst during thermal treatment has also been reported (Fernandez et al 1995). In the doped $\mathrm{TiO}_{2}$ films, treated at $700^{\circ} \mathrm{C}$, presence of significant quantity of rutile phase could be explained by the combined effect of $\mathrm{Sn}$ dopant as well as $\mathrm{Fe}$ and $\mathrm{Cr}$ ions, which are penetrated in the $\mathrm{TiO}_{2}$ films from the steel substrate. It was proved by XPS analyses that the dopant concentration in the basic layer is slightly lower than that in the sol solution. Figure 6 presents XPS spectra of Ti2 $p$ and $\mathrm{Sn} 3 d$ of $\mathrm{TiO}_{2}-20 \mathrm{~mol} \%$ $\mathrm{SnO}_{2}$ sol-gel films on stainless steel, annealed at $500^{\circ} \mathrm{C}$. The concentration of oxygen, titanium and tin in the $\mathrm{TiO}_{2}$ films after sol-gel procedures and treatment are 69.8, 12 and 11.6 at $\%$, respectively. We have evaluated the crystallites size of the films on the basis of well known Scherrer's equation. In our opinion these values are more representative than the microscopic photographs. By TEM or AFM method, we can gather information about the grains size, which consisted of crystallites. The data in table 1 reveal that the addition of $\mathrm{SnO}_{2}(10-50 \mathrm{~mol} \%)$ reduces slightly the grain dimensions due to the grain growth inhibition. A similar phenomenon was also observed by other workers (Zakrzewska 2001). The dimensions of the rutile crystallites were found to be very small $(4-4.5 \mathrm{~nm})$, while the anatase crystallites have a size $12 \cdot 5-17 \mathrm{~nm}$.

\section{Conclusions}

In this report we proved that the crystalline phase transformation from anatase to rutile is promoted by the increase of $\mathrm{SnO}_{2}$ content in the $\mathrm{TiO}_{2}$ films and the heat-treatment temperature. It was also found that the type of substrate has a significant influence on the phase composition and anatase phase stability. Anatase crystallites in the sol-gel $\mathrm{TiO}_{2}-\mathrm{SnO}_{2}$ films deposited on quartz substrates were found to be more stable as compared to the stainless steel substrate. This phenomenon might come from the impurity effects of $\mathrm{SiO}_{2}$ provided by the quartz substrate. In the case of sol-gel films deposited on stainless steel, the rutile peaks appeared at $500^{\circ} \mathrm{C}$. For the films treated at $700{ }^{\circ} \mathrm{C}$, the presence of significant quantity of rutile phase might be explained by the combined effect of Sn dopant as well as $\mathrm{Fe}$ and $\mathrm{Cr}$, which penetrated into the $\mathrm{TiO}_{2}$ films from steel substrate. It is interesting to highlight that those very small dimensions of rutile crystallites $(4 \mathrm{~nm})$ have been obtained for $\mathrm{TiO}_{2}$ films doped with $10-50 \mathrm{~mol} \% \mathrm{SnO}_{2}$.

\section{Acknowledgement}

The authors thank to the Bulgarian Ministry of Science and Education for financial support by way of a project grant No. DDVU 02-36/10.

\section{References}

Buska G, Ramis G, Amores J M C, Escribano S and Plaggio P 1994 J. Chem. Soc. Faraday Trans. 903181

Ding X -Z, Qi X -Z and He Y -Z 1994 Nanostruct. Mater. 4663

El-Maghraby E M 2010 Physica B405 2385

Fallet M, Mahdjoub H, Gauter B and Bauer J-P $2001 \mathrm{~J}$. Non-Cryst. Solids 293-295 527

Fernandez A, Lassaletta G, Jimknez V M, Justo A, Gonzalez-Elipe A R, Herrmann J -M, Tahiri H and Ait-Ichou Y 1995 Appl. Catal. B: Environ. 749

Garzella G, Comini E, Tempesti E, Frigeri C and Sberveglieri G 2000 Sensor Actuator B68 189

Gennari F C and Pasquevich D M 1998 J. Mater. Sci. 331571 
Habibi M H, Nasr-Estafani M and Egerton T A 2007 J. Mater. Sci. 426027

Hoffman M R, Martin S I, Choi W and Bahnemann D W 1995 Chem. Rev. 9569

Kanai N, Nuida T, Ueta K, Hashimoto K, Watanabe T and Ohsaki H 2004 Vacuum 74723

Kaya C, Kaya F, Su B, Thomas B and Boccaccini A R 2005 Surf. Coat. Technol. 191303

Kumar K N, Fray D J, Nair J, Mizukami F and Okubo T 2007 Scr. Mater. 57771

Lin J, Yu J C, Lo D and Lam S K 1999 J. Catal. 183368

Liu K, Wu X, Wang B and Liu Q 2002 Mater. Res. Bull. 37 2255

MacKenzie K J D 1975 Trans. J. Br. Ceram. 7429

Maeda M and Hirota K 2006 Appl. Catal. A302 305

Mahanty S, Roy S and Sen S 2004 J. Cryst. Growth 26177

Miyauchi M, Nakajama A, Watanabe T and Hashimoto K 2002 Chem. Mater. 142812

Nikolic L, Radonic L and Srdic V V 2005 Ceram. Int. 31 261
Peshev P, Stambolova I, Vassilev S, Stefanov P, Blaskov V, Starbova K and Starbov N 2003 Mater. Sci. Eng. B97 106

Shen Y, Tao J, Gu F, Huang L, Bao J, Zhang J and Dai N 2009 J. Alloys Compd $\mathbf{4 7 4} 326$

Stambolova I, Blaskov V, Vassilev S, Shipochka M and Dushkin C 2010 J. Alloys Compd 489257

Tai W -P and Oh J -H 2002 Sensor Actuator $\mathbf{B 8 5} 154$

Traversa E, Gnoppi G and Montenegro A 1996 Sensor Actuator B31 59

Tu Y -F, Huang S -Y, Sang J -P and Zou X -W 2009 J. Alloys Compd 482382

Yang J, Li D, Wang X, Yang X and Lu L 2002 Solid State Chem. 165193

Yoshinaka M, Hirota K and Yamaguchi O 1997 J. Am. Ceram. Soc. 802749

Zakrzewska K 2001 Thin Solid Films 391229

Zhang H and Banfield J F 2000 J. Phys. Chem. 1043481

Zhang Yu -H and Reller A 2002 Mater. Sci. Eng. C19 323

Zhou M, Yu J, Liu S, Zhai P and Jiang L 2008 J. Hazard. Mater. 1541141 